\title{
Structural Features of Electrodeposited Metals as a Result of Ultra-Rapid Solidification of a Highly Supercooled Liquid Metal Phase
}

\author{
Oleg B. Girin \\ Department of the Materials Science, Ukrainian State University of Chemical Technology, Dnipropetrovsk, Ukraine
}

Email address:

girin@ua.fm

To cite this article:

Oleg B. Girin. Structural Features of Electrodeposited Metals as a Result of Ultra-Rapid Solidification of a Highly Supercooled Liquid Metal Phase. Advances in Materials. Special Issue: Advances in Electrodeposited Materials: Phase Formation, Structure and Properties.

Vol. 4, No. 3-1, 2015, pp. 33-40. doi: 10.11648/j.am.s.2015040301.15

\begin{abstract}
With a view to validating the existence of the phenomenon of phase formation via a liquid state stage in metals being electrodeposited, experiments were carried out to reveal electrodeposited metal's structural features typical of metals produced by solidification at ultra-high rates under high supercooling, and to establish consistent changes in metal structural characteristics with increasing degree of supercooling in electrodeposition. Following experimental facts in favour of the existence of the phenomenon in point were found: (1) occurrence of spherulites and pentagonal quasicrystals in electrodeposit layers adjoining the cathode, the occurrence being typical of metals produced by ultra-rapid solidification of a highly supercooled liquid metal phase; (2) emergence of the electrodeposited metals solely in a spherulitic form when transition of spherulitic growth to drusy growth with increasing deposit thickness was prevented; and (3) regular change in characteristics of point, linear and planar defects in the crystalline lattice with increasing degree of supercooling in electrodeposition of metals.
\end{abstract}

Keywords: Structure, Phase Formation, Electrodeposited Metal, Spherulite, Quasicrystal, Crystalline Defect

\section{Introduction}

The existence of phenomenon of phase formation via a liquid state stage in metals being electrodeposited has been confirmed by experimental data in numerous reports [1-12]. Still, the unconventional nature of this phenomenon requires additional approaches to experimental validation of its existence. In this context, the intention of the investigation at hand was to perform further experimental verification of the existence of the discovered phenomenon by analysis of electrodeposited metals' structural features as resulting from ultra-rapid solidification of highly supercooled liquid metal phase.

The general idea of this study was that the structure in metals that were ultra-rapidly solidified under high supercooling has certain typical traits that distinguish it from the metals' structure evolved under ordinary conditions. Besides, the degree of supercooling in metal electrodeposition must be a major factor that may affect qualitative characteristics of the structure. Should it be established that electrodeposited metal structure displays features peculiar to metals produced by ultra-rapid solidification of supercooled liquid metal phase and the metals' structural characteristics change consistently with rising degree of supercooling during electrodeposition, then these facts will serve as additional proofs of the existence of the phenomenon in point.

\section{Experimental Proof of the Existence of the Phenomenon}

\subsection{Idea One and Its Realization}

It is well-known that metal solidification at a minor degree of melt supercooling follows a dendritic pattern due to morphological instability at solid-melt interface. At high supercooling, however, dendritic solidification gives way to spherulitic one [13, 14], the latter form featuring radially divergent crystals. As shown on metal ingot samples produced by solidification at high supercoolings, the spherulites generally occur at the metal-crucible interface $[15,16]$.

At ultra-rapid melt cooling rates, spherulites take a dominating role in the solidification [17-19]. Additionally, quasicrystals with a pentagonal symmetry occur in ultra-rapid quenching of highly supercooled melts [20-22], which feature 
aperiodic long range order of atom arrangement and absence of translational symmetry.

Therefore, if metals indeed pass a supercooled liquid state stage during electrodeposition and are rapid-quenched at the deposition temperature, then their layers adjacent to the cathode should contain spherulitic aggregates and pentagonal quasicrystals. The occurrence of these forms, typical of melts quenched at very high rates under high supercooling, in cathode-adjacent deposit layers will serve as a proof of the existence of the phenomenon discovered.

\subsubsection{Materials and Methods}

To prove this idea, cathode-adjacent layers in electrodeposited copper, lead and cobalt were investigated. For easy separation of the metal deposits, the cathodes were made in the form of polished stainless steel plates. Table 1 lists electrolyte compositions and deposition conditions for the metals used.

Table 1. Electrolytes composition and parameters of electrodeposition of metals.

\begin{tabular}{|c|c|c|c|}
\hline Metal & $\begin{array}{l}\text { Electrolytes } \\
\text { Composition, g L }{ }^{-1}\end{array}$ & $\begin{array}{l}\text { Electrolyte } \\
\text { Temperature, }{ }^{\circ} \mathrm{C}\end{array}$ & $\begin{array}{l}\text { Current } \\
\text { Density, } \mathbf{A ~ d m}^{-2}\end{array}$ \\
\hline $\mathrm{Cu}$ & $\begin{array}{l}\mathrm{CuSO}_{4} \cdot 5 \mathrm{H}_{2} \mathrm{O}-250 \\
\mathrm{H}_{2} \mathrm{SO}_{4}-100\end{array}$ & 25 & $0.4-0.6$ \\
\hline $\mathrm{Pb}$ & $\begin{array}{l}\mathrm{Pb}\left(\mathrm{BF}_{4}\right)_{2}-150 \\
\mathrm{HBF}_{4}-60 \\
\mathrm{H}_{3} \mathrm{BO}_{3}-25\end{array}$ & 25 & $0.8-1.0$ \\
\hline Co & $\begin{array}{l}\mathrm{CoSO}_{4} \cdot 7 \mathrm{H}_{2} \mathrm{O}-300 \\
\mathrm{NaCl}-3 \\
\mathrm{H}_{3} \mathrm{BO}_{3}-6\end{array}$ & 25 & $0.1-0.3$ \\
\hline
\end{tabular}

Surface morphology of cathode-adjacent metal layers was studied by secondary electron imaging using type REhM-106I scanning electron microscope. The ultimate pressure in the SEM column in the vicinity of the electron gun did not exceed $6.7 \cdot 10^{-4} \mathrm{~Pa}$, the gun current was $98 \mathrm{~mA}$.

\subsubsection{Results and Discussion}

Spherulites were revealed in the cathode-adjacent layers of the electrodeposited metals under study (Fig. 1). In copper deposits (Fig. 1 $a, b, c$ ), the spherulites displayed faceted pyramidal crystals grown radially from common centre. The spherulites in electrodeposited lead (Fig. $1 d, e, f$ ) had a radial platy make-up as different from the spherulites in cobalt with their radiating petalous morphology (Fig. $1 g, h, i$ ). Characteristically, the spherulitic forms in grain aggregates of the cathode-adjacent layers all featured a radially divergent pattern and common centre [23].

Quasicrystals with a fifth order symmetry axis not allowed in the classical crystallography were found in the cathode-adjacent layers of metal electrodeposits as well (Fig. 2). Similarly to the spherulites, the quasicrystals exhibited a peculiar make-up for each of the metals studied [23]. For example, the pentagonal quasicrystals in copper displayed faceted pyramidal forms (Fig. 2a) while those in lead were of radial platy type (Fig. $2 b$ ).
The presence of multiple forms in spherulites and pentagonal quasicrystals readily identified in metal layers contacting substrate is a demonstration of the validity of the proposed concept of phase formation via emergence and ultra-rapid solidification of a highly supercooled metallic liquid during electrochemical deposition of metals. The development of spherulites and pentagonal quasicrystals in electrodeposited metals can be explained as follows.

According to the proposed concept, the liquid state of a metal being electrodeposited is due to an extremely rapid, burst-like nature of its liberation resulting from a chain reaction of electrochemical evolution of atoms [1]. An average of 40 to 60 atoms evolve in one burst-like growth event. Since such an event has a duration of just about $10^{-7} \mathrm{~s}$, the atoms have no time to build a long range ordered structure $[1]$.

The multitude of such liquid atomic clusters avalanching at various sites near the surface of cathode or of growing deposit constitute liquid phase of the metal being electrodeposited, said phase being in a highly supercooled condition [1]. Ultra-rapid solidification of this highly supercooled metallic liquid leads to occurrence of spherulites and pentagonal quasicrystals in electrodeposited metals as experimentally observed (Fig. 1 and 2).

It should be noted that development of spherulites and pentagonal quasicrystals in layers of electrodeposited metal adjacent to the cathode has been reported already. For instance, transmission electron microscopy revealed spherulites in electrodeposited copper [24] as well as in cobalt and nickel electrodeposits [25]. There are also reports on investigations of quasicrystals having pentagonal symmetry and found in face-centred cubic metal electrodeposits [26-28]. It is pentagonal quasicrystals that build core of the spherulites and act as crystallization nuclei [29].

The present author has carried out experiments to reveal spherulites and pentagonal quasicrystals in electrodeposited metals with the aim of experimentally validating the existence of the phenomenon in point. Since the experiments revealed structural features of these types and these findings are supported by literature data cited above, it may be concluded that ultra-rapid solidification of supercooled liquid metallic phase does take place in electrochemical deposition of metals.

Reports are available [30-33] in which the emergence of quasicrystals with pentagonal symmetry and variety of structural types (amorphous or perfect crystalline) in an electrodeposited metal are explained by the metal's attaining of a high-temperature "liquid phase" state and subsequently cooling down during its electrodeposition. For example, some papers [30-32] on phase formation in electrodeposited copper show that "... the temperature in the growing islet, if its size is within a certain range, rises abruptly due to peculiarities of heat exchange in electrocrystallization (and can thus exceed copper melting point) and then drops down to the substrate temperature..." [32]. 


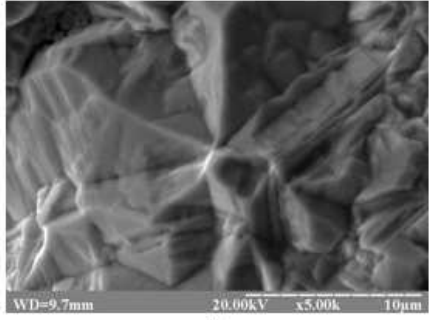

(a)

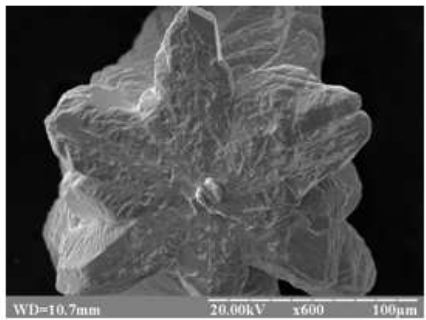

(d)

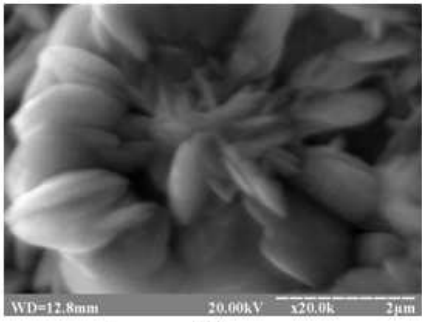

(g)

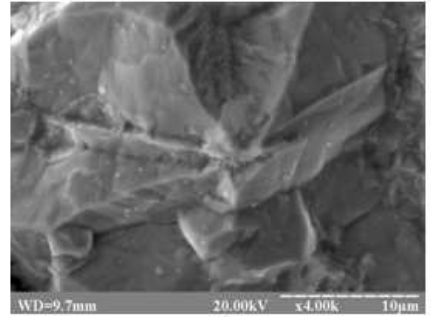

(b)

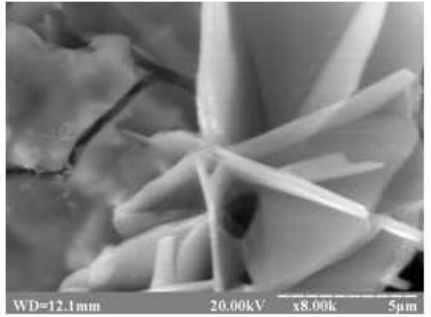

(e)

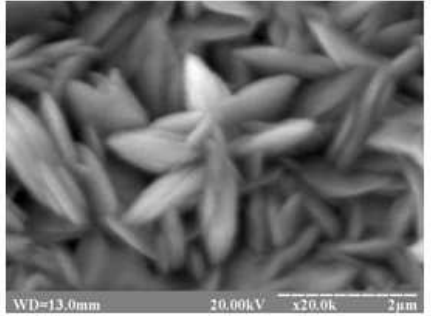

(h)

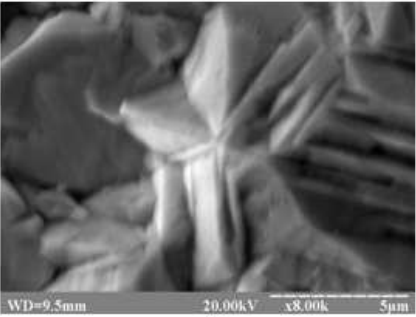

(c)

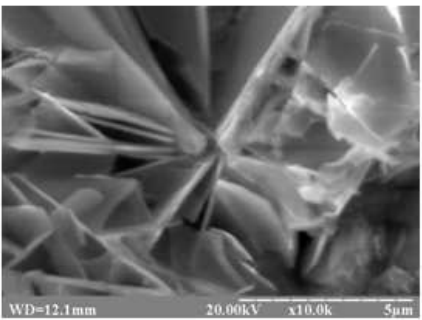

$(f)$

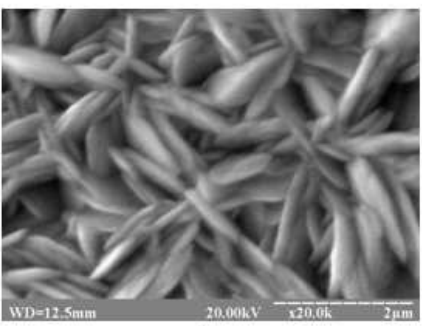

(i)

Figure 1. SEM images of cathode-adjacent layers in metal electrodeposits showing occurrence of spherulites in copper (a), (b), (c), lead (d), (e), ( $f$ ) and cobalt (g), (h), (i).

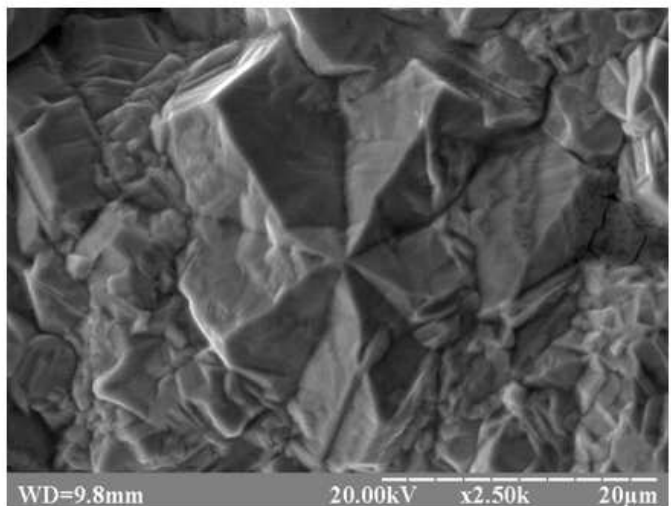

(a)

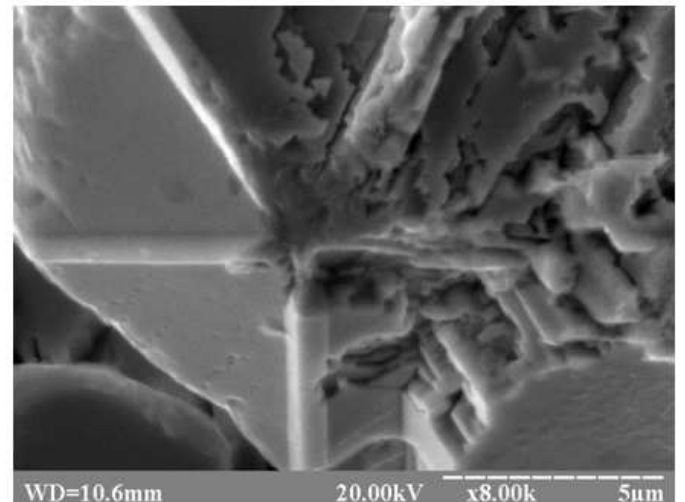

(b)

Figure 2. SEM images of cathode-adjacent layers in electrodeposited metals illustrating occurrence of pentagonal quasicrystals in copper (a) and lead (b).

Assuming that a metals being electrodeposited from water solutions indeed solidifies from a molten state due to some growing islets reaching the metal's melting point, one should contemplate islet growth stoppage at above $100^{\circ} \mathrm{C}$ because of a film of vapour which will emerge around the islet surface. Considering that islet number is about $10^{5} \mathrm{~cm}^{-2}$ [34], it may be expected that the electrochemical deposition process will be completely stopped as soon as the growing islets' temperature has reached the water boiling point.

Furthermore, if metals pass a high-temperature liquid state stage during electrodeposition, they will, during solidification in the absence of a high supercooling, assume dendritic, rather than spherulitic forms and produce no pentagonal quasicrystals. In this context, the mechanism of phase formation in metals being electrodeposited as suggested in [30-33] appears unlikely.

The occurrence of spherulites and pentagonal quasicrystals in electrodeposited metals is caused by ultra-rapid solidification of a highly supercooled liquid metal phase evolving during the electrochemical deposition. This finding is another proof of the existence of the phenomenon of phase formation via a liquid state stage in metals being 
electrodeposited.

\subsection{Idea Two and Its Realization}

It is well-known that with highly supercooled melts, metal in layers adjacent to the crucible solidifies in a spherulitic manner which turns into a drusy one with the advance of the solidification front and, accordingly, with the decrease in supercooling degree [15-18]. A similar pattern can be observed during phase formation in a metal being electrodeposited, when metal layers adjacent to the cathode contain spherulites $[24,25]$. As the deposited layer grows in thickness, the spherulites disappear and the deposit then develops in druse form.

It was shown in the preceding section that the spherulite occurrence in electrodeposited metals results from ultra-rapid solidification of a highly supercooled liquid metal phase appearing in the course of the electrochemical deposition. For a more convincing argument in favour of the existence of an intermediate liquid phase in metal being electrodeposited, one should completely prevent transition from the spherulitic growth process to the drusy one with increasing thickness of deposit and thus produce a purely spherulitic deposit.

The formation of a purely spherulitic electrodeposit typical of metals that solidified from a liquid state at a very fast rate under high supercooling will be a proof of the existence of the phenomenon discovered.

\subsubsection{Experiment Justification}

According to current views, a spherulite is a crystal growth form resulting from crystal splitting at an initial growth stage and subsequent spreading of the multiple fine subindividuals radially with geometric selection [35-37].

Spherulites emerge readily in a medium containing impurities because they are incorporated by a nucleating crystal and lead to saturation of crystalline defects in its lattice under conditions of accelerated growth. Accumulation of defects in a growing crystal brings about its splitting which leads to formation of spherulites [35].

Taking into account that phase formation via a liquid state stage in electrodeposited metals takes place under high supercooling $[1,2]$, in order to preclude the possibility of spherulitic growth transition to a drusy form as the deposit gets thicker, one should provide and maintain conditions during crystallization that favour accelerated crystal growth accompanied by an abundant accumulation of crystalline defects.

Accelerated crystal growth can be achieved during electrodeposition by increasing current density which is in proportion with the deposition rate; accumulation of defects in crystals can be facilitated by doping the electrolyte with elements capable of impeding lattice building in emerging crystals.

Increased current densities are employed in electrodeposition of transition metals, namely chromium, manganese, iron, cobalt and nickel. Of these, chromium and iron have the least tightly packed crystal lattice (body centred cubic, atomic packing factor 0.68 ) offering itself more readily to saturation of defects at temperatures comparable to electrodeposition temperature. Of these two metals, iron has a structure which is more susceptible to various elements' effects in electrodeposition; hence the choice of iron as the model metal.

Nickel and chromium were selected as alloying additions to iron in electrodeposition upon the following grounds. Nickel has a face centred lattice which is basically different from the iron lattice and its atomic radius is much smaller than that of iron (0.1377 vs. $0.1411 \mathrm{~nm})$. Chromium, although similar to iron in lattice type, has an atomic spacing that appreciably exceeds that of iron ( $0.2498 \mathrm{vs} .0 .2483 \mathrm{~nm})$.

It should thus be expected that electrodeposition involving complex alloying of iron with nickel and chromium will cause iron-based substitution solution clusters to build a crystalline lattice with a high saturation of defects as these clusters solidify from a liquid state. The abundant presence of crystalline defects in nucleating crystals' lattice will favour crystal splitting to multiple fine subindividuals in the form of blocks.

Subsequent block spreading radially will lead to occurrence of radial divergent crystals, that is spherulites. Continuous nickel and chromium alloying in iron being electrodeposited at an increased current density will prevent transition from the spherulitic to drusy growth form with increasing deposit thickness, thus resulting in deposits composed solely of spherulites.

\subsubsection{Materials and Methods}

The above idea was realized in complex alloying of iron with nickel and chromium [38] during electrodeposition under conditions given in Table 2. Deposit thickness was varied from 5 to $50 \mu \mathrm{m}$, the substrate material was steel, grade $08 \mathrm{kp}$. Reference specimens were produced by iron electrodeposition under similar conditions with no additions of salts of nickel or chromium to the electrolyte.

Table 2. Electrolytes composition and parameters of electrodeposition of alloyed iron and iron without alloying.

\begin{tabular}{llll}
\hline $\begin{array}{l}\text { Electrolytes } \\
\text { Composition, } \mathbf{g ~ L}^{-1}\end{array}$ & $\begin{array}{l}\text { Electrolyte } \\
\text { Temperature, }\end{array}{ }^{\circ} \mathbf{C}$ & $\begin{array}{l}\text { Current } \\
\text { Density, } \mathbf{A ~ d m}^{-2}\end{array}$ & $\mathbf{p H}$ \\
\hline $\begin{array}{l}\mathrm{FeSO} \\
\mathrm{Al}_{2} \cdot 7 \mathrm{SO}_{2} \mathrm{O}-400\end{array}$ & 55 & 10 & $2-3$ \\
$\mathrm{NiSO}_{4} \cdot 7 \mathrm{H}_{2} \mathrm{O}-100$ & & & \\
$\mathrm{Cr}_{2}\left(\mathrm{SO}_{4}\right)_{3} \cdot 6 \mathrm{H}_{2} \mathrm{O}-96$ & & & \\
$\mathrm{FeSO}_{4} \cdot 7 \mathrm{H}_{2} \mathrm{O}-400$ & 55 & 10 & $2-3$ \\
$\mathrm{Al}_{2}\left(\mathrm{SO}_{4}\right)_{3} \cdot 18 \mathrm{H}_{2} \mathrm{O}-100$ & & & \\
\hline
\end{tabular}

Specimen surface morphology and elemental composition were investigated using Type REhM-106I scanning electron microscope having an energy-dispersive X-ray system. Degree of saturation of crystalline lattice by defects was estimated from diffraction peak width and intensity obtained in an upgraded diffractometer DRON-3 using $\mathrm{Cu}-\mathrm{K}_{\alpha}$ radiation.

\subsubsection{Results and Discussion}

The data obtained showed that electrodeposition of iron alloyed with nickel and chromium produced deposits that 
consisted of iron-based substitutional solid solution with $1.74 \% \mathrm{Ni}$ and $1.27 \% \mathrm{Cr}$. The complex transition metal alloying lead to considerable crystalline defect saturation in electrodeposited iron lattice, as confirmed by lower diffraction intensities and broader diffraction peaks as compared to those of nonalloyed iron deposits [38].

For example, (110) diffraction peak for alloyed electrodeposited iron, Fig. $3 a$, displays a 2.5 times smaller intensity and a $30 \%$ greater broadening than a similar peak for nonalloyed iron, Fig. $3 b$.

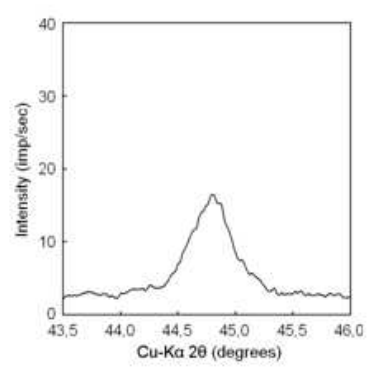

(a)

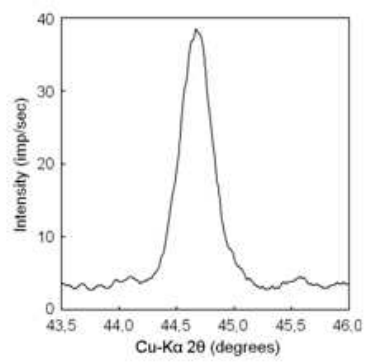

(b)
Figure 3. The curves of the intensity distribution in the $\{110\}$ diffraction peak for iron electrodeposits $15 \mu \mathrm{m}$ thick: (a) alloyed by nickel and chromium; (b) - without alloying.

Changes of similar manner in intensities and broadening

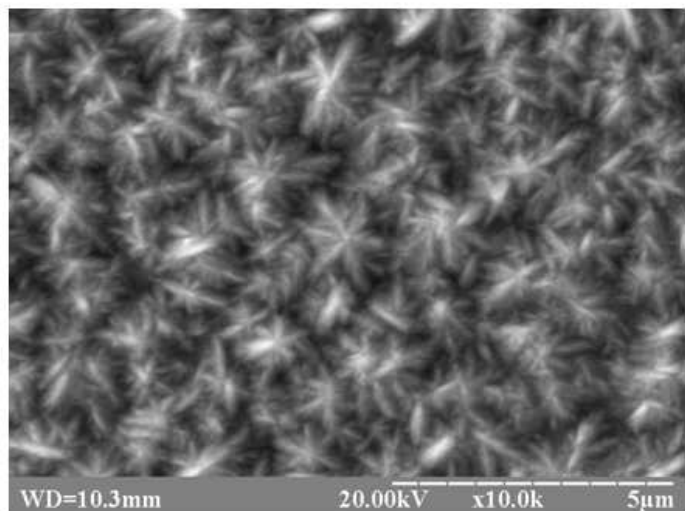

(a) were observed with other diffraction peaks measured on specimens of iron alloyed during electrodeposition. Hence, complex alloying of electrodeposited iron with transition metals brings about both mosaic block refining and microdeformations in the lattice of emerging solid solution crystals.

Since linear defects in metals are mainly concentrated at block and grain boundaries, substructure refinement brings about enrichment of crystalline defects in the alloyed iron lattice. Accumulation of crystalline defects in the lattice during growth leads to crystal splitting which results in continual emergence of new spherulites against the background of development of those already in existence. A highly nonuniform distribution in spherulite size may thus be anticipated with increasing deposit thickness.

Fig. 4 confirms this suggestion. With $5 \mu \mathrm{m}$ in thickness, the alloyed iron deposits contained very small spherulites; with 15 $\mu \mathrm{m}$, some larger spherulites and fine spherulitic formations are observed. Further development of the deposit to a thickness of $50 \mu \mathrm{m}$ in circumstances where transition to drusy growth was precluded was accompanied by both coarsening of previously existing spherulites due to geometric selection and emergence of new ones (Fig. 4a). This resulted in a nonuniform spherulitic structure basically different from drusy form of electrodeposited metal appearing in electrodeposition of nonalloyed iron, see Fig. $4 b$ [38].

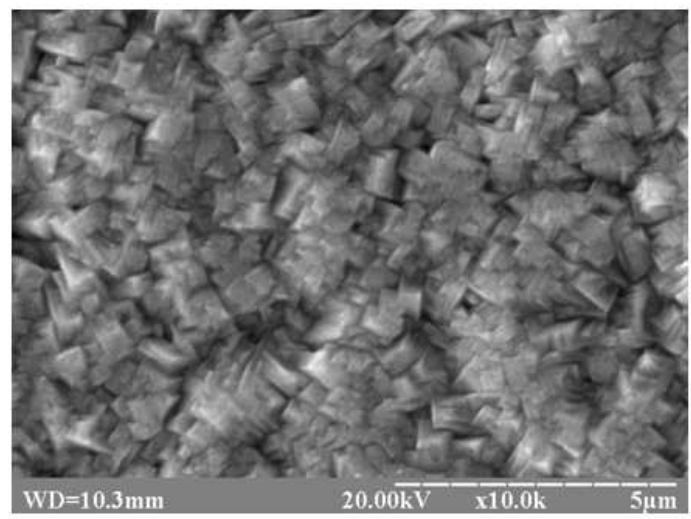

(b)

Figure 4. SEM images of Ni-Cr-alloyed (a) and nonalloyed (b) iron electrodeposits $50 \mu \mathrm{m}$ thick.

As seen from Fig. 4, the model experiment yielded alloyed electrodeposited iron specimens that consisted solely of spherulites.

Thus one more proof of the existence of the phenomenon of phase formation via a liquid state stage is offered for metals being electrodeposited, namely the occurrence of electrodeposited metal in a purely spherulitic form typical of metals that were solidified very rapidly from a liquid state under high supercooling.

\subsection{Idea Three and Its Realization}

Based on the concept of phase formation via a supercooled liquid state stage in metals being electrodeposited, it may be expected that the enrichment of crystalline defects will increase with higher supercooling $\Delta T$ in electrodeposition. This is because the high nucleation rate at greater $\Delta T$ values dominates over the linear crystal growth rate.

Accordingly, increasing $\Delta T$ must lead to higher vacancy concentrations, greater dislocation densities and smaller grain sizes in metals being electrodeposited. Regular changes in characteristics of point, linear and planar crystalline defects with higher supercooling during metal electrodeposition will serve as a proof of the existence of the phenomenon in point.

\subsubsection{Materials and Methods}

The above idea was verified in experiments on a number of metals $(\mathrm{Co}, \mathrm{Cr}, \mathrm{Cu}, \mathrm{Fe}$ and $\mathrm{Ni}$ ) which were deposited under 
ordinary conditions from ordinary electrolytes with no organic additions. At first approximation, the difference between the metal's melting point and electrodeposition temperature was regarded as the degree of supercooling $\Delta T$. Since current density affects crystalline defect generation as well, several current density values corresponding to a soft, an intermediate and a hard mode of electrodeposition were selected for each degree of supercooling.

As characteristic of crystalline defects, vacancy concentration was used for point defects and average dislocation density for linear ones; the enrichment of planar defects was estimated from the metal's average grain size. Positron annihilation was used for measuring the vacancy concentration. Angular distribution of annihilation photons was determined using a point-line geometry unit having an angular resolution of $1 \mathrm{mrad}[39,40]$.

The dislocation density was evaluated by X-ray diffraction analysis using upgraded X-ray diffractometers DRON-3 and DRON-3M with selected monochromatic radiation (respectively, $\mathrm{Cu}-\mathrm{K}_{\alpha}, \mathrm{U}=20 \mathrm{kV}, \mathrm{I}=30 \mathrm{~mA}$ and $\mathrm{Mo}-\mathrm{K}_{\alpha}, \mathrm{U}=20$ $\mathrm{kV}, \mathrm{I}=35 \mathrm{~mA}$ ). The average grain size was determined using a PEhM-100 type transmission electron microscope with digital signal recording and a combined brightfield and darkfield technique [41-45]. The values of dislocation density and grain size were averaged over all texture components with due account of relative contributions, using a method reported earlier [45].

\subsubsection{Results and Discussion}

The experiments revealed that the degree of supercooling in electrodeposition has a pronounced effect on vacancy concentration in metals [40]. It can thus be seen from Table 3 that increasing $\Delta T$ by about $400 \mathrm{~K}$ (by changing test metal) resulted in a vacancy concentration rise by an order of magnitude.

Table 3. Change of vacancy concentration in metals with the increase of supercooling degree during electrodeposition.

\begin{tabular}{llll}
\hline Metal & $\begin{array}{l}\text { Supercooling } \\
\text { degree, } \mathbf{K}\end{array}$ & $\begin{array}{l}\text { Current } \\
\text { Density, } \mathbf{A ~ d m}^{-2}\end{array}$ & $\begin{array}{l}\text { Vacancy } \\
\text { Concentration }\end{array}$ \\
\hline $\mathrm{Ni}$ & 1430 & 6 & $10^{-4}$ \\
& & 8 & $5 \cdot 10^{-4}$ \\
& & 10 & $10^{-3}$ \\
$\mathrm{Co}$ & 1470 & 15 & $5 \cdot 10^{-4}$ \\
& & 30 & $8 \cdot 10^{-4}$ \\
& & 45 & $10^{-3}$ \\
$\mathrm{Fe}$ & \multirow{2}{*}{1510} & 20 & $10^{-3}$ \\
& & 35 & $5 \cdot 10^{-3}$ \\
$\mathrm{Cr}$ & \multirow{2}{*}{1835} & 50 & $8 \cdot 10^{-3}$ \\
& & 20 & $10^{-3}$ \\
& & 35 & $5 \cdot 10^{-3}$ \\
& & 50 & $10^{-2}$ \\
\hline
\end{tabular}

The degree of supercooling in electrodeposition had a great deal to do with dislocation density in metals too. Table 4 shows that increasing $\Delta T$ by about $750 \mathrm{~K}$ (by changing test metal) lead to a rise in the average dislocation density by three orders of magnitude.
Table 4. Effect of supercooling degree during electrodeposition on dislocation density in metals.

\begin{tabular}{llll}
\hline Metal & $\begin{array}{l}\text { Supercooling } \\
\text { degree, } \mathbf{K}\end{array}$ & $\begin{array}{l}\text { Current } \\
\text { Density, } \mathbf{A ~ d m} \mathbf{~ d m}^{-2}\end{array}$ & $\begin{array}{l}\text { Average } \\
\text { Dislocation Density, } \mathbf{c m}^{-2}\end{array}$ \\
\hline $\mathrm{Cu}$ & 1058 & 0.5 & $2.7 \cdot 10^{9}$ \\
& & 3.5 & $2.3 \cdot 10^{9}$ \\
& & 6.5 & $5.8 \cdot 10^{9}$ \\
$\mathrm{Ni}$ & \multirow{2}{*}{1390} & 2.5 & $1.9 \cdot 10^{10}$ \\
& & 7.5 & $4.2 \cdot 10^{10}$ \\
& & 12.5 & $7.3 \cdot 10^{10}$ \\
$\mathrm{Fe}$ & \multirow{2}{*}{1510} & 10 & $9.8 \cdot 10^{10}$ \\
& & 20 & $2.6 \cdot 10^{11}$ \\
& & 30 & $4.4 \cdot 10^{11}$ \\
$\mathrm{Cr}$ & \multirow{2}{*}{1810} & 30 & $9.3 \cdot 10^{11}$ \\
& & 50 & $2.6 \cdot 10^{12}$ \\
& & 70 & $5.8 \cdot 10^{12}$ \\
\hline
\end{tabular}

Table 5 demonstrates how the degree of supercooling in electrodeposition influenced average grain size in the metals. It is seen that grain refinement by an order of magnitude took place as the degree of supercooling was increased by approximately $750 \mathrm{~K}$ (by changing test metal).

Table 5. Dependence of grain size in metals on supercooling degree during electrodeposition.

\begin{tabular}{llll}
\hline Metal & $\begin{array}{l}\text { Supercooling } \\
\text { degree, } \mathbf{K}\end{array}$ & $\begin{array}{l}\text { Current } \\
\text { Density, } \mathbf{A ~ d m}^{-2}\end{array}$ & $\begin{array}{l}\text { Average Grain } \\
\text { Size, } \boldsymbol{\mu m}\end{array}$ \\
\hline $\mathrm{Cu}$ & 1058 & 0.5 & 2.0 \\
& & 3.5 & 3.0 \\
& & 6.5 & 1.7 \\
$\mathrm{Ni}$ & \multirow{2}{*}{1390} & 2.5 & 0.8 \\
& & 7.5 & 0.9 \\
& \multirow{3}{*}{1470} & 12.5 & 0.6 \\
$\mathrm{Co}$ & & 10 & 0.7 \\
& & 25 & 0.6 \\
& \multirow{3}{*}{1810} & 40 & 0.5 \\
$\mathrm{Cr}$ & & 30 & 0.4 \\
& & 50 & 0.2 \\
& & 70 & 0.1 \\
\hline
\end{tabular}

Clearly, the consistent change in characteristics of point, linear and planar crystalline defects with increasing degree of supercooling during electrodeposition is another proof of the phenomenon of phase formation via a liquid state stage in metals being electrodeposited.

\section{Conclusion}

Analysis of experimental data starting from a new conceptual basis has made it possible further to elucidate processes that take place in phase formation of metals being electrodeposited. It has been established that spherulites and pentagonal quasicrystals occur in cathode-adjacent metal layers, which is typical of metals produced by ultra-rapid solidification of a highly supercooled liquid metal phase. It has been shown that electrodeposited metals appear solely in spherulitic form if transition from spherulitic to drusy growth form with increasing deposit thickness is prevented completely. Consistent change has been found in characteristics of point, linear and planar crystalline defects as degree of supercooling is increased in electrodeposition. The above experimental results prove the existence of the 
phenomenon of phase formation via a liquid state stage in metals being electrodeposited.

\section{References}

[1] O. B. Girin, "Phenomenon of precipitation of metal being electrodeposited, occurring via formation of an undercooled liquid metal phase and its subsequent solidification. Part 1. Experimental detection and theoretical grounding," in Materials Development and Processing, vol. 8, J. V. Wood, L. Schultz, and D. M. Herlach, Eds. Weinheim: WILEY-VCH, 2000, pp. 183-188. doi: 10.1002/3527607277.ch30

[2] O. B. Girin, "Phenomenon of precipitation of metal being electrodeposited, occurring via formation of an undercooled liquid metal phase and its subsequent solidification. Part 2. Experimental verification," in Materials Development and Processing, vol. 8, J. V. Wood, L. Schultz, and D. M. Herlach, Eds. Weinheim: WILEY-VCH, 2000, pp. 189-194. doi: 10.1002/3527607277.ch31

[3] O. B. Girin, "Phenomenon of structure formation of metals being electrodeposited via a super-cooled metal liquid, and its use for the development of advanced technologies of depositing new types of protective composite coats on canned food steel sheet," in Proc. of the 5th Int. Sci. Forum AFES. Paris: Int. Acad. of Engn, 2004, pp. 142-147.

[4] O. B. Girin, "Structure formation of metals being electrodeposited through a metal liquid as a tool for surface quality upgrading of canned food steel sheet," in Proc. of the 6th Int. Sci. Forum AFES. Hong Kong: Int. Acad. of Engn, 2005, pp. 101-103.

[5] O. B. Girin, "Phase transformations in the metallic materials being electrodeposited," in Proc. of the 7th Int. Sci. Forum AFES "DAVOS FORUM". Davos: Int. Acad. of Engn, 2006, pp. 76-81.

[6] O. B. Girin, "Phase transformations in the metallic materials being electrodeposited and their application for the development of advanced technologies for anticorrosive protection of canned-food steel sheet," Mater. Sci. Forum., vol. 561-565, pp. 2369-2372, 2007.

[7] O. B. Girin, "Phase and structure formation of metallic materials electrodeposited via a liquid state stage: new experimental proof," Defect Diffus. Forum, vol. 303-304, pp. 99-105, 2010.

[8] O. B. Girin, "Change of density and surface morphology of metals being electrodeposited under the action of a centrifugal force," The Adv. Sci. J., issue 3, pp. 11-16, 2011.

[9] O. B. Girin, "Formation of the deposits of metals being electrodeposited under the influence of a centrifugal force," The Adv. Sci. J., issue 4, pp. 51-58, 2011.

[10] O. B. Girin, "Phase formation through a stage of liquid state in metallic materials being electrodeposited: recent experimental proofs," Int. J. Mater. Sci., vol. 2 (4), pp. 108-118, 2012.

[11] O. B. Girin, "Crystallographic texture formation in metals being electrodeposited at the external force influence," Amer. J. Mater. Sci., vol. 4 (3), pp. 150-158, 2014. doi: 10.5923/j.materials.20140403.06

[12] O. B. Girin, "Structure features of metals obtained by electrochemical deposition and by solidification from liquid state in saturated hydrogen environment," Chem. Mater. Eng., vol. 2 (5), pp. 119-126, 2014. doi: 10.13189/cme.2014.020503

[13] I. S. Miroshnichenko, Quenching from Liquid State. Moscow: Metallurgy, 1982, 168 p. (In Russian).

[14] A. M. Glezer and I. E. Permyakova, Melt-Quenched Nanocrystals. Boca Raton: CRC Press, 2013, 369 p.

[15] G. L. F. Powel and L. M. Hogan, "The undercooling of copper and copper-oxygen alloys," Trans. Metall. Soc. AIME, vol. 242 (10), pp. 2133-2138, 1968.

[16] C. Caesar, "Undercooling and crystal growth velocity during rapid solidification," Adv. Eng. Mater., vol. 1 (1), pp. 75-79, 1999.

[17] V. O. Yesin, V. A. Sazonova, and I. A. Zablotskaia, "Spherulite form of crystallization in metals," IZV AN SSSR MET, issue 2, pp. 73-77, 1989 (In Russian).

[18] L. Granasy, T. Pusztai, G. Tegze, J. A. Warren, and J. F. Douglas, "Growth and form of spherulites," Phys. Rev. E, vol. 72 (1), 011605, 2005.

[19] J.-P. Andreassen, E. M. Flaten, R. Beck, and A. E. Lewis, "Investigations of spherulitic growth in industrial crystallization," Chem. Eng. Res. Des., vol. 88, pp. 1163-1168, 2010 .

[20] D. Shechtman, I. Blech, D. Gratias, and J. W. Cahn, "Metallic phase with long-range orientational order and no translational symmetry," Phys. Rev. Lett., vol. 53 (20), pp. 1951-1954, 1984.

[21] A. P. Tsai, "Icosahedral clusters, icosaheral order and stability of quasicrystals - a view of metallurgy," Sci. Technol. Adv. Mater., vol. 9, pp. 1-20, 2008.

[22] Yu. Kh. Vekilov and M. A. Chernikov, "Quasicrystals," Physics-Uspekhi, vol. 53 (6), pp. 537-560, 2010.

[23] O. B. Girin and V. I. Ovcharenko, "Formation of spherulites and pentagonal quasicrystals in metals being electrodeposited," Eastern-European Journal of Enterprise Technologies, issue 2/11, pp. 30-34, 2014 (In Russian).

[24] Ye. A. Mamontov, L. A. Kurbatova, and A. P. Volenko, "Formation of spherulites during electrocrystallization of copper on indifferent substrates," Electrochemistry, vol. 19 (11), pp. 1546-1549, 1983 (In Russian).

[25] Ye. A. Mamontov, L. A. Kurbatova, and A. P. Volenko, "Spherulites as form of growth of electrolytic deposits," Electrochemistry, vol. 21 (9), pp. 1211-1214, 1985 (In Russian).

[26] Ye. A. Mamontov and L. A. Kurbatova, "Formation of pentagonal crystals in electrolytic deposits of copper and disclinations," Electrochemistry, vol. 28 (5), pp. 746-753, 1992 (In Russian).

[27] A. A. Vikarchuk, "Classification of structures being formed during electrocrystallization of metals with face-centered cubic lattice," Electrochemistry, vol. 28 (7), pp. 974-982, 1992 (In Russian).

[28] A. A. Vikarchuk and A. P. Volenko, "Pentagonal copper crystals: various growth shapes and specific features of their internal structure," Phys. Solid State, vol. 47 (2), pp. 352-356, 2005. 
[29] Ye. A. Mamontov, "About the possibilities of disclination analysis of structure of electrodeposited metals," Electrochemistry, vol. 30 (2), pp. 170-173, 1994 (In Russian).

[30] A. A. Vikarchuk, A. P. Volenko, and V. I. Skidanenko, "Model of the initial stage of electrocrystallization of copper on indifferent substrates," Izv. Russ. Akad. Nauk. Fiz., vol. 68 (10), pp. 1384-1390, 2004 (In Russian).

[31] A. A. Vikarchuk and I. S. Yasnikov, "Specific features of mass and heat transfer in microparticles and nanoparticles formed upon electrocrystallization of copper," Phys. Solid State, vol. 48 (3), pp. 577-580, 2006.

[32] A. A. Vikarchuk and I. S. Yasnikov, "Phase Transitions in Small Particles Formed at the Initial Stages of Electrocrystallization of Metals," Phys. Solid State, vol. 49 (1), pp. 1-5, 2007.

[33] A. A. Vikarchuk, Yu. D. Gamburg, and I. S. Yasnikov, "Temperature evolution for small particles formed during electrocrystallization,” Russ. J. Electrochem., vol. 44 (7), pp. 857-860, 2008

[34] A. A. Vikarchuk, A. P. Volenko, Yu. D. Gamburg, and V. I. Skidanenko, "Initial stage in three-dimensional nucleation of pentagonal crystals," Russ. J. Electrochem., vol. 41 (9), pp. 996-1000, 2005.

[35] N. I. Krasnova and T. G. Petrov, Genesis of Mineral Individuals and Agregates. St. Petersburg: Nevsky Courier, 1995, 228 p. (In Russian).

[36] T. Pusztai, G. Bortel, and L. Granasy, "Phase field theory of polycrystalline solidification in three dimensions," Europhys. Lett., vol. 71 (1), pp. 131-137, 2005.

[37] L. Granasy, L. Ratkai, A. Szallas, B. Korbuly, G. I. Toth, L. Kornyei, and T. Pusztai, "Phase-field modeling of polycrystalline solidification: from needle crystals to spherulites - a review," Metall. Mater. Trans. A, vol. 45 (4), pp. 1694-1719, 2014.

[38] O. B. Girin and Ie. V. Kolesnyk, "Formation of metal being electrodeposited solely in spherulitic form," Eastern-European Journal of Enterprise Technologies, issue 6/11, pp. 26-29, 2014 (In Russian).

[39] H.-J. Hunger, Selected Research Techniques in Physical Metallurgy. Moscow: Metallurgy, 1985, 490 p. (In Russian).

[40] O. B. Girin and I. M. Kovenskiy, "Features of formation of the defects of crystalline structure of metals being electrodeposited," Eastern-European Journal of Enterprise Technologies, issue 2/5, pp. 44-47, 2012 (In Russian).

[41] O. B. Girin, V. P. Khlyntsev, and G. M. Vorob'ev, "Investigation into substructure of chromium electrodeposits," Izv. AN SSSR Met., issue 4, pp. 169-171, 1988 (In Russian).

[42] O. B. Girin and V. P. Khlyntsev, "An unusual contrast in electron micrographs of electrodeposited chromium layers," Electrochemistry, vol. 22 (9), pp. 1249-1250, 1986 (In Russian).

[43] O. B. Girin and V. P. Khlyntsev, "Nonhomogeneity of intragranular structure in nickel electrodeposits," Izv. AN SSSR Met., issue 6, pp. 150-152, 1990 (In Russian).

[44] O. B. Girin, "Substructure formation and texture in electrodeposits," J. Electron. Mater., vol. 24 (8), pp. 947-953, 1995.

[45] O. B. Girin, Yu. O. Proshenko, and E. P. Kalinushkin, "Texture of electrodeposited copper coatings as related to their substructure, granular structure and surface morphology," Texture Microstruct., vol. 34 (2-3), pp. 171-179, 2000. 